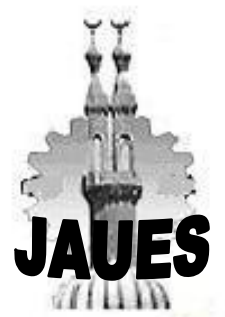

Journal of Al-Azhar University Engineering Sector

Vol.17, No.62, January, 2022, 345-354

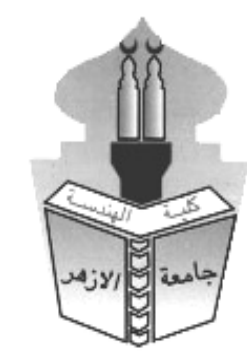

\title{
USING SMART MATERIALS IN SMART WINDOWS FOR ENERGY EFFICIENCY OF BUILDINGS
}

\author{
Ahmed Abdel-Moneim ${ }^{1, *}$, Morad AbdelKader ${ }^{2}$ \\ ${ }^{1}$ Master student, Department of Architecture - Faculty of Engineering - Ain Shams University. \\ ${ }^{2}$, Department of Architecture - Faculty of Engineering - Ain Shams University. \\ *Corresponding Author E-mail: Ahmed.moneim94@gmail.com \\ Received :22 Sept. $2021 \quad$ Accepted:16 Dec. 2021
}

\begin{abstract}
Due to ecological system problems, there is a result of increasing importance of energy efficiency, new technologies have been innovated. Like smart windows are transparent glass surfaces that allow you to control the amount of heat and light that passes through them while still allowing you to see out. In case of lighting and air conditioning, the emerging interactive windows, particularly electro chromic glazing are promising to be more energy efficient than conventional static devices, also high-performance dynamic glass panel systems prevent heat loss and monitor received sun emission to enhance receiving heat energy in winter and reduce receiving heat energy in summer, all of them provide maximum natural illumination with no glare. At last this study examines the several categories of interactive windows available on marketplace, including operational mechanism, and emphasizes their potential uses and contributions in terms of resource conservation, ecological safety, and design to attain that perfectly from both modern building and up skilling projects.
\end{abstract}

Keywords :Intelligent glass panels, adaptive glass panels, developing glazing innovations, adaptable architectural envelopes, and architectural resource consumption.

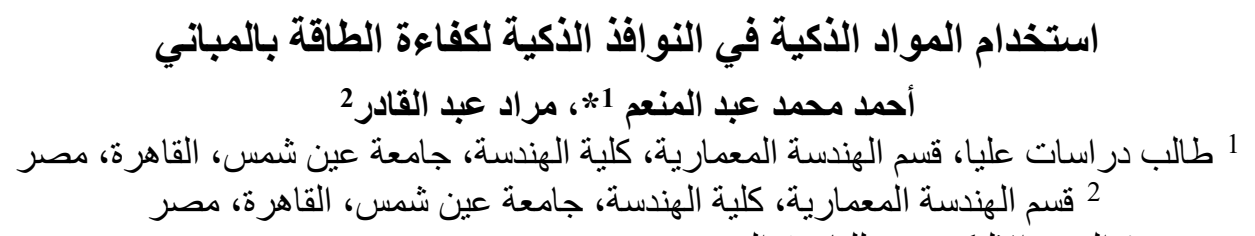

Ahmed.moneim94@gmail.com البريد الاليكتروني اللباحث الرئيسنة:

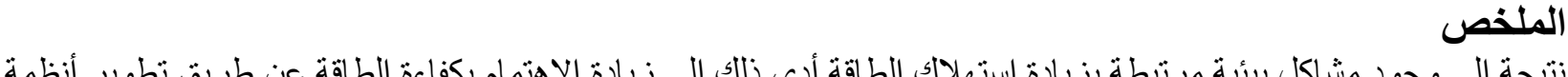

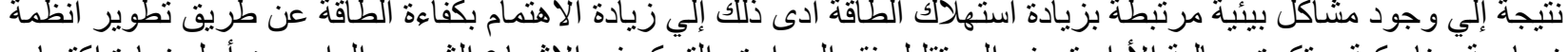
زجاجية ديناميكية مبتكرة و عالية الأداء تهدف إلى تقليل فقد الحرارة والتحكم في الإشعاع الثمسي الوارد من أجل زيادة اكتساب 


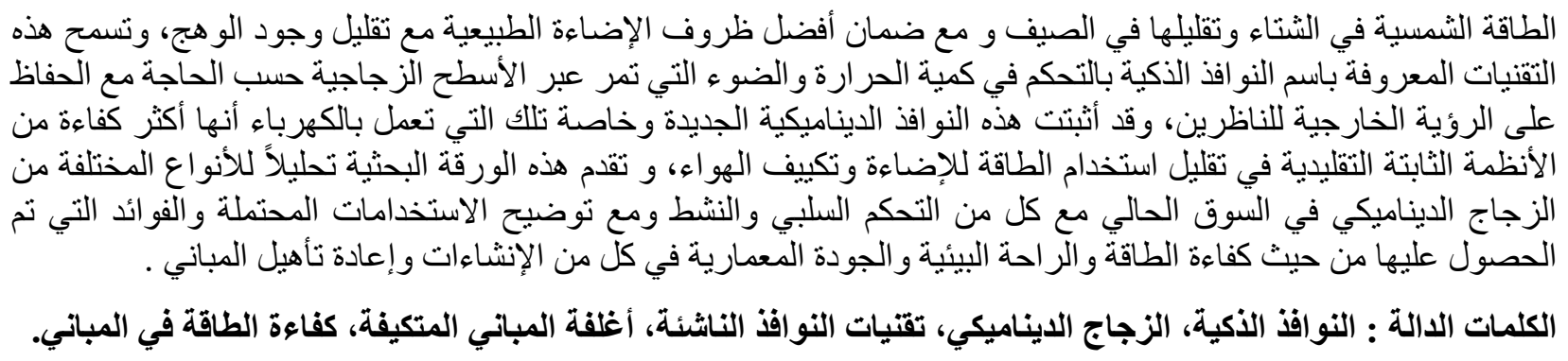

\section{INTRODUCTION}

Smart materials are active surfaces and responsive platforms that contain actuators, sensors, or shape-shifting qualities that allow them to respond to internal and external situations. Their ability to self-reconfigure to modify the identity of interior spaces through a range of shapes, immediacy, transiency function, and directness define them. Some materials have the ability to modify one or more of their properties in response to an external source of energy (thermal, electrical, mechanical, chemical, and magnetic). The transition might occur naturally or be prompted by the user. Their primary behavior or reaction is chemical, with only a thin exterior layer thickened. As a result of the variation in the chemical reaction, a number of these changes occur in their visual properties, such as the color and shape of the material, while in other situations, the material is exposed to transfer one type of energy to another as a result of the energy exchanging reaction.

The main objective of gathering the rising claim aimed at thermo-hygrometric and ecological safety, as well as the insistent really have to increase construction resource conservation in order to reach "greenhouse gas steady", is to perform a thorough examination of improving external features and specifications, emphasizing the importance of technology systems that help for continual modification.

The architectural external shell is essential to building's energy performance and has a significant impact on the inside environment's wellness. It is a sophisticated classification of walls and ecological strainers capable of regulating thermal, sunlight, airflow and water vapor, and also the conversion of radiant energy to energies necessary for construction respiration

Under this specific situation, the translucent component of the construction facades can serve an important as a climatological classifier between the indoor and outdoor ecosystems, balancing natural light with switched wellness management requires and decrease overall requirements for ventilation and brightness.

Emerging interactive glass panels, which can continually alter efficiency and brightness emission qualities in response to outdoor ecological situations and user demands, are now the alternative in emerging implementation and architectural upgrades. These technologies, when combined with illumination and ventilation condition controllers, have the potential to save significant energy and reduce environmental impact while also improving inhabitants' sight and heat satisfaction.

\section{RESEARCH PROBLEM}

Transparent solutions, on the other hand, necessitate precise redesign that is concentrated on ecological situation features, incorporation with industrial devices, and measure progress; or else, the translucent layer might become building's main origin of ecological dissatisfaction and power scattering. According to United States Department of Energy, ineffective windows lose between $25 \%$ and $35 \%$ of the energy in buildings. According to the California Energy Commission, solar heat gain through windows accounts for about $40 \%$ of a typical building's cooling requirement. [2] 
Conventional stable solar energy management technologies are failing to meet regulatory goals of energy efficiency and environmental well-being while restricting independence of attending through usage of translucent mechanisms. Emerging interactive glass panels, which are often employed extensively in Europe, particularly in dual façade design, hinder outside visibility and are often unsuitable for energy retrofits due to higher installation, operation, and maintenance costs.

So the research problem lies in the lack of interest in rationalizing energy consumption through using external windows. Since the materials used in the external window get a major effect on internal environment of spaces of these constructions, so the lack of choosing materials that reduce heat transfer to the internal environment leads to an increase in the energy consumption required to achieve an environment comfortable interior.

\section{RESEARCH METHODOLOGY}

Furthermore, the continuous use of natural materials in traditional construction methods will almost certainly result in the depletion of these resources as a result of their widespread use. As a result, it was required to design construction processes using a variety of materials in order to achieve the environmental dimension and cost-effective solutions while also ensuring resource sustainability. The methodology used in this study is based on an analytical and descriptive approach to identifying advanced smart windows, their characteristics, and their uses.

- Descriptive analytical method: establishing the theoretical framework of innovative smart windows and their selection impact.

- Comparative analytical approach: according to market availability these evaluate smart windows implementations and qualities through energy efficiency.

\section{SOLAR RADIATION CONTROL IN BUILDINGS}

Controlling incident sun radiation is a critical component of achieving Thermal comfort and, extra widely, increased power conservation in dwellings.

Thermal gain absorption through glass panel can help to reduce power use for indoor warming in the winter. In the summertime, particularly in hot climates and those with a Tropical weather, excess ultraviolet irradiance entering through to the glazing may create warming of the internal climate, leading to increase cooling consumption.

Direct solar radiation can be a hindrance to visual activities in the indoor environment, particularly for facades facing the east and west directions, which are influenced by moderate and strong direct sunlight, necessitating the application of filtering technologies as well as modern illumination technologies even with very high outdoor illumination intensity. The UV component of direct solar radiation is ultimately responsible for the decomposition of furnishing and inside finishing.

Sunlight control can be enforced using conventional fixed devices, such as solar prevention glass panels or portable shading panels equipment, or complex technologies, which can be incorporated and organized with constructing services and consist of electronic portable solar panels or interactive glass panels that can alter their spectral features in reply to sunlight emissions.

\subsection{Static Solar Protection Glazing}

Solar protection glazing, as opposed to basic higher heat insulating material dual glass panels for thermal energy loss decreasing, has the task of preventing the most of incoming radiated light from entering inside through the glass panels.

Embodiment pigmented glass panels, thermal degradation treated glass, and preferential strong glazed windows with "magnetron" type treatments are three types of high-performance glazing 
available on the market. When compared to the first, the latter allows for better energy transmission control without sacrificing visible light transmission. The spectral selectivity index, also known as LSG (Light to Solar Gain Ratio) index, describes the relationship between light transmittance (VLT) and solar heat gain coefficient (SHGC): Windows with such a significant LSG conducts a substantial proportion of incoming sunlight but a tiny part of overall emission. Spectacular glasses are now on marketplace with apparent transmittances ranging from 34\% to 69\%, solar heat gain coefficients ranging from $24 \%$ to $56 \%$, and a selectivity index (LSG) ranging from 1.28 to 2.29. [2]

In the summer, Fixed sun block glass minimizes thermal absorption while preserving visibility and lowering glare. These kinds of technologies, on the other hand, do not allow for the monitoring of daily sun trajectories, weather conditions, or season changes, resulting in lower Wintertime solar collection (especially on the south-facing facades) and decreased day lighting sources in the lack of sun light (especially for the west-facing facades).

\subsection{Static and Dynamic Protecting Technologies}

Outdoor shade components, like directional projected vents, blinds, shades, or curtains, are desirable when be used as indoor shading elements since these filter the sun's rays when they enter the property. However, it is critical to assess the performance of such devices because their existence can considerably alter the act of apertures and hence the ventilation factor of spaces.

Indoor features, on the other hand, like shades or shutters, act largely by deflecting and spreading the sunlight outside, collecting a substantial portion and causing heat to be released inside the indoor environment. In any case, these factors are effective at preventing glare.

Outer shading systems, if appropriately constructed, can give differential behavior throughout the year time, blocking thermal radiation in the summertime while allowing entrance during the wintertime.

With advancement of building automation technologies, which are becoming increasingly common, particularly in new buildings, dynamic screening systems may now modify both architectural form and the quantity of energy from the sun are controlled based on environmental conditions. These technologies are typically manufactured with embedded changeable louvers into a double-skin shading devices, particularly in Europe.

However, the use of screening technologies, including interactive ones, while operative in maintaining thermal energy in winter, reducing thermal energy gain in summer, and eliminating glare in relation to outdoor daylight situations and user desires, may result in an excessive decrease of inside day lighting, while not allowing outdoor sight and being unsuitable for energy retrofit. Such systems also have higher implementation, supervision, and servicing costs.

\subsection{Dynamic Glazing}

There is an interest to maintain varied energy and lighting necessities is influencing be using of upcoming goods including such chromogenic translucent coatings, which effects on the function and interactive influence of heat radiation and illumination while also changing their spectral features in reaction to illumination, electronic power, heat transfer, or biological stimulation.

Using of transparent chromogenic coatings in architecture enables realizing of translucent enclosures with changeable efficiency, defined emerging interactive glass panels, capable of optimizing building energy behavior while meeting user comfort needs.

\section{SMART WINDOWS}


Intelligent glass is classified into two types based on how it operates: active command (adjusted towards the customer's demands) and inactive command (self-automated).

\subsection{Passive Dynamic Glazing}

Static interactive technologies do not require electricity stimulation to function. These systems react autonomously to ecological factors including light (photochromic windows) or thermal energy (thermo chromic and thermo tropic windows). In comparison to active technologies, these therefore are quicker to setup and even more stable, despite inability to be controlled by the user on demand.

\subsubsection{Photochromic glazing}

In reaction to the intensity of incident light, photochromic glass can vary its transparency qualities. This is due to the presence of organic or inorganic compounds in the glass paste that act as "visual photosensitizer," including such halides (chloride and silver bromide) that are sensitive to ultra violet (UV) radiation, or plastics that receive the sun's rays based on color spectral variation during production. Once photochromic material is continuously subjected to sunlight, a reversible process of vivid coloration occurs owing to the variation in wavelength absorbance between both the radiation glass panels and other materials. Response time to environmental changes is a few minutes, and the shift from colored to transparent requires double as much. Such discrepancies in react speed might cause issues if the outdoor brightness varies frequently and abruptly, or they may cast reflections on the property, resulting in irregular and unsightly brightness and shade patches. Additionally, after the chromatic shift, photochromic coating remains receptive instead of reflective, increasing the danger of glass pane overheating and heat transfer stress rupture in the presence of excessive sun rays. [3]

\subsubsection{Thermo-chromic glazing}

Thermochromic (TC) glazing can change its optical properties autonomously in response to the heat of the outer layer, which specifies a biochemical process or a phase change among different phases. When temperatures are lower than the transition value, the material remains transparent but at rising temperature, it turns milky. (as shown in Fig. 1). Typically, the changeover temp is between $10^{\circ} \mathrm{C}$ (highest opacity) and $65^{\circ} \mathrm{C}$. (Lowest opacity). The qualities of thermochromism can be seen in a broad variety of biological and mineral materials, as well as metal oxide coatings such as vanadium oxide: transitioning out of a transistor to a conductive phase results in a reflected response that is very responsive in the infrared (IR) region.
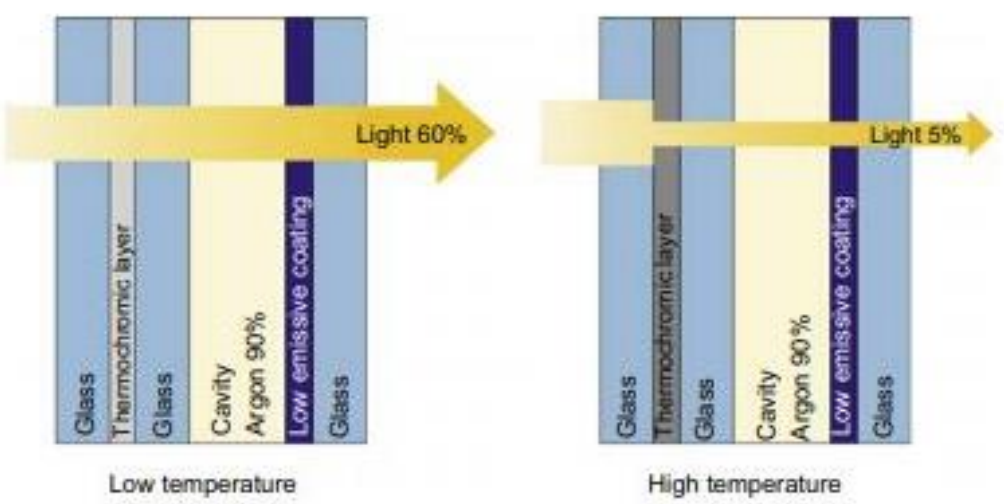

Figure 1. Thermo chromic glazing operating scheme. 
Through integration of thermo chromic substances embedded in a polyvinyl butyral (PVB) plastic layer with a thickness of $1.2 \mathrm{~mm}$ is the best significant technological technique for the implementation of this tinting at the moment. Because PVB is the most often employed materials in the manufacture of multilayered protection or acoustical glazing, this technique provides for the optimum combination of production operations as well as the opportunity of achieving higher quality output at a lower price. [3]

The regular daylight propagation and thermal mass change in correlation with translucent and opaque phases, once it paired with glass panels with transient response of these few seconds. [3]

\subsection{Active Dynamic Glazing}

Adjustments in outdoor conditions (heat, sunlight) or indoor conditions (heat, synthetic and normal sunlight thresholds, thermal consumption, user needs) could be completely determined or through an automated control device, allowing the concentration of perforating observable and infrared radiation to be adjusted. Technologies that incorporate to photovoltaic panels can provide main power independence, as well as the ability to control them remotely through the use of cellphones, enable separate alteration of various frames within that glass panel, and have the potential of becoming true visualization expressions with touch - screen technological advancements. [3]

\subsubsection{Electro chromic devices (EC)}

Electro chromic glazing uses the ability of certain coatings to alter the characteristics of solar radiation propagation, absorption, and penetration in response to an externally adjusted electrical stimulus. The inclusion or removal of free ions from the electro chromic coating causes changes in the characteristics of these elements: when the electric field is activated, the injected ions react, forming compounds that change the color of the material.

The central part of an electrochromic device is an ionic conducting placed among two films, an electrochromic film (called as an electrodes) and an accumulated film. Despite the fact that the two outer films are translucent active coatings, the charged particle gathering layers and the translucent conductors can be integrated into an unified film. When there is an electricity between the two translucent conducts, ions from the accumulated film move through the conductor layer and into the electrochromic coating, affecting its visual characteristics (as shown in fig.2).
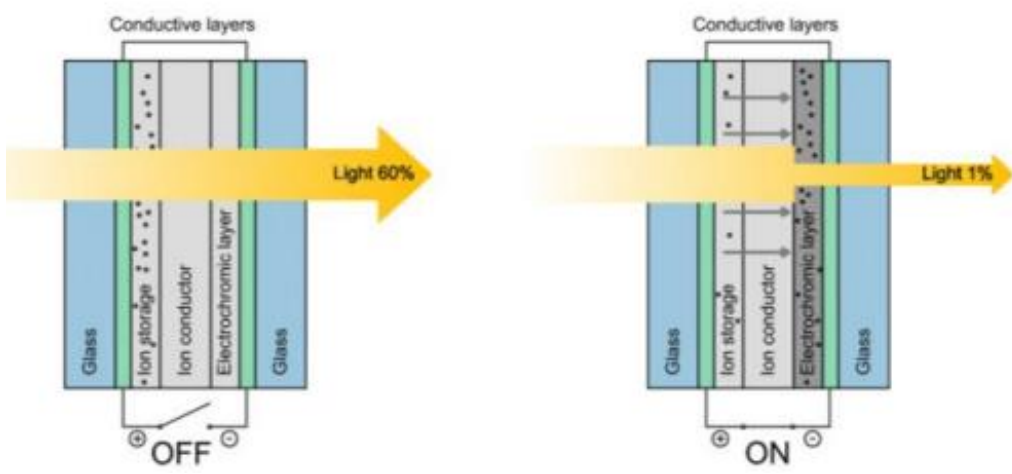

Figure 2. Electro chromic glazing operation

In comparison to the most commonly used electrochromic materials (in particular, tungsten oxide, differs in hue from translucent to blue.), available glazing has typically green or blue colors, and the grade of clearness can be controlled in transitional states ranging from clear (off the device ) 
to fully colored. Light transmission ranges from $60 \%$ in a clear condition to $1 \%$ in a cloudy one (as shown in fig.3).

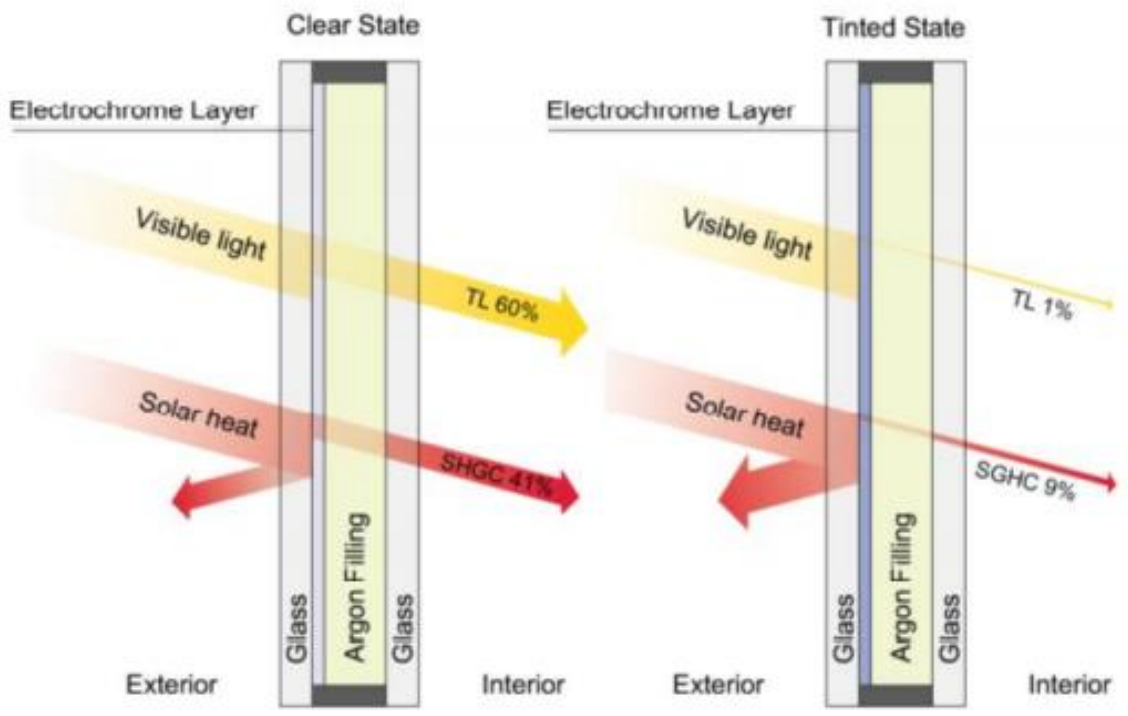

Figure 3. Electro chromic glazing

The prospect of increasing the quantity of management modes as well as the transition rate, increasing cloudiness in colored mode for promoting solitude, as well as significantly lowering the existing scarce power usage are all technological areas for advancement for electro chromic glass.

\subsubsection{Suspended particle devices}

SPDs are made from a double transparent glass layer with a coating of fine laminated colloidal nanoparticles, similarly to sticks, submerged in liquid and placed between two conducting materials composed of clear flimsy plastic material. The attached rod components aligned when the electricity is turned on, enabling passage of lighting through and the SPD intelligent window to be transparent. So when system is switched off, the particles spontaneously cluster, obstructing the illumination and giving the window a dark (or cloudy) blue, grey, or black color. SPD glass can brighten or darkened, providing for voltage or current applied of the quantity of direct sunlight going through (Fig. 4). When it's darkness outside, SPD device can filter up to $99 \%$ of optical wavelengths. Finally, whether switched open or closed, SPD glass defends against damaging UV radiation. [3]
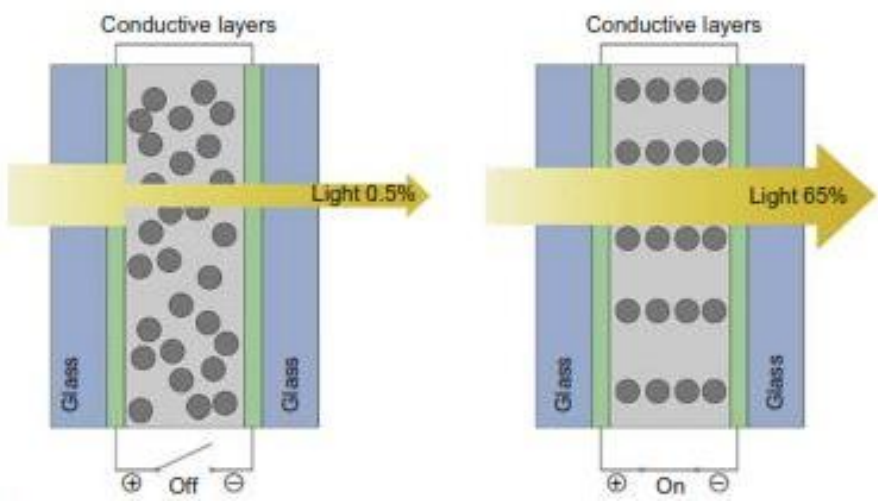

Figure 4. Suspended particle devices operating scheme. 
From off to transparent, the system requires around $100 \mathrm{~V}$ AC and modulable toward any transitional condition. The continuous transmission energy need is $0.55 \mathrm{~W} / \mathrm{m}^{2}$ and the switching power requirement is $5 \mathrm{~W} / \mathrm{m}^{2}$. Long-term stability and visual light qualities were not confirmed because of items are unknown to the marketplace, however the high price continues to be an issue.

\subsubsection{PDLC devices}

A liquid crystal method comprises of two sheets of glass that support a PDLC package consisting of a polymeric layer placed between two conductive material on clear flimsy plastic layers. Microscopic fluid crystalline particles with sizes on the absolute scale of apparent photon spectra are dispersed inside this multilayer.

The particles are disturbed in the lack of an electrified signal, causing random diffractions in crossing light beams and attempting to make coated components turn brighter and visible; whenever an electricity generation is given, the particles realign in the identical way, guaranteeing the materials' visual quality (Fig. 5). The degree of transparency can be altered by varying the applied voltage. The light transmittance of liquid crystal glazing does not often surpass $70 \%$ in the active state and hovers around $50 \%$ in the off state, though proper pigments could be applied to dim the device in the close phase. Although liquefied particle devices disperse straight incoming thermal energy effectively, they already don't filter it effectively to significantly lower the solar factor. In privacy-sensitive applications, PDLC systems are typically used to create interior or external walls. PDLC products are supplied in rolled sheets as a sealant, personalized smart coating with built-in Wi-Fi control that can be applied to existing windows. [3]
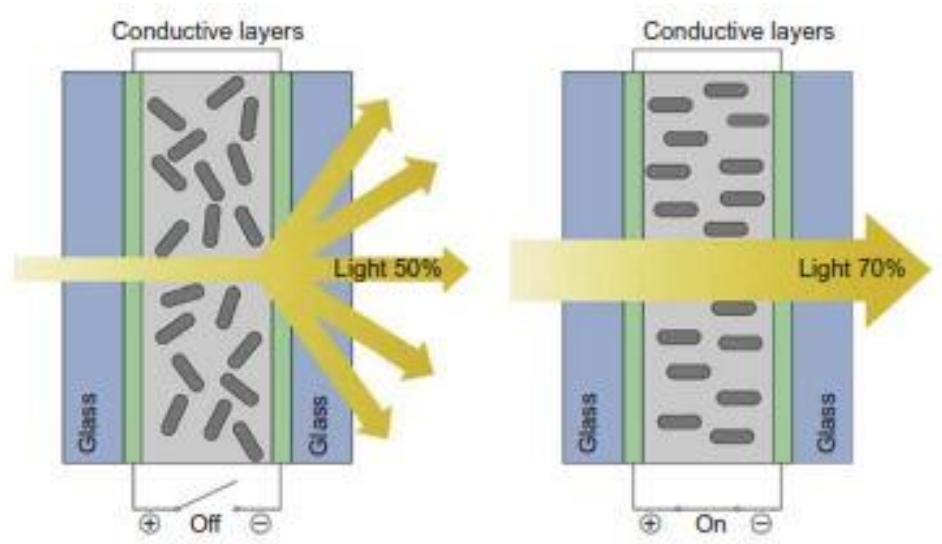

Figure 5. Mechanism for running a polymer-dispersed liquefied particles system.

\section{COMPARISON ANALYSIS}

As described above for each type of dynamic glazing Table 1 expresses a evaluation of the most popular active and inactive chromogenic glass paneling on the marketplace.

\begin{tabular}{|c|c|c|c|c|}
\hline \multirow{3}{*}{ Properties } & \multicolumn{3}{|c|}{ Interactive glass paneling } & \\
\hline & \multirow{2}{*}{$\begin{array}{c}\begin{array}{c}\text { Inactive } \\
\text { technologies }\end{array} \\
\text { TC } \\
\end{array}$} & \multicolumn{3}{|c|}{ Active technologies } \\
\hline & & EC & SPD & PDLC \\
\hline \multicolumn{5}{|c|}{ Heat and visual efficiency } \\
\hline $\begin{array}{l}\text { Obvious Light Diffusion } \\
\text { (Bright) }\end{array}$ & $60 \%$ & $60 \%$ & $65 \%$ & Up to $75 \%$ \\
\hline $\begin{array}{c}\text { Obvious Light Diffusion } \\
\text { (Bright) }\end{array}$ & $5 \%$ & $1 \%$ & $0.5 \%$ & $50 \%$ \\
\hline
\end{tabular}


USING SMART MATERIALS IN SMART WINDOWS FOR ENERGY EFFICIENCY OF BUILDINGS

\begin{tabular}{|c|c|c|c|c|}
\hline SGHC (Bright) & 0.37 & 0.46 & 0.57 & 0.06 \\
\hline SGHC (Shady) & 0.12 & 0.06 & 0.55 \\
\hline Forms & $\begin{array}{c}\text { Any form, } \\
\text { especially curved } \\
\text { shapes }\end{array}$ & $\begin{array}{c}\text { Rectangle, square, } \\
\text { trapezoid, triangle }\end{array}$ & $\begin{array}{c}\text { Any form, with } \\
\text { perforations at any } \\
\text { location and curved }\end{array}$ & $\begin{array}{c}\text { Any form, with } \\
\text { perforations } \\
\text { anywhere and } \\
\text { curved }\end{array}$ \\
\hline Tints & $\begin{array}{c}\text { Blue, Green, } \\
\text { Bronze, Gray }\end{array}$ & Blue, Green & Blue & $\begin{array}{c}\text { Clear, Bronze, } \\
\text { Gray, Green }\end{array}$ \\
\hline \multicolumn{7}{|c|}{ Electrical Characteristics } \\
\hline Power of operation & n/a & 12 V DC & 65-110 V AC & 65-110 V AC \\
\hline Operating speed & Several minutes & $\begin{array}{c}\text { Usually 3 to 5 } \\
\text { minutes }\end{array}$ & $\begin{array}{c}\text { Usually 1 to 3 } \\
\text { seconds }\end{array}$ & Direct (0.1 sec) \\
\hline Control & No & $\begin{array}{c}\text { Wall switch, Remote } \\
\text { control, Movement } \\
\text { sensor, Light and } \\
\text { heat sensor, Timer }\end{array}$ & $\begin{array}{c}\text { Wall switch, Remote } \\
\text { control, Movement } \\
\text { sensor, Light and } \\
\text { heat sensor, Timer }\end{array}$ & $\begin{array}{c}\text { Wall switch, } \\
\text { Remote control, } \\
\text { Movement sensor, } \\
\text { Light and } \\
\text { heat sensor, Timer }\end{array}$ \\
\hline \multicolumn{7}{|c|}{ Expenses and lifespan } \\
\hline Expenses & Lowest & Medium & Highest & High \\
\hline lifespan & >20 years & >30 years & >20 years & $>10$ years \\
\hline
\end{tabular}

According to the need of the usage these specify the required features from previous types. If we need better optical and thermal performance, we can use PDLC glazing in clear state for more light transmission in some spaces, while in dark state we can use themochromics (TC) glazing for more privacy requirements. According to cost and durability TC is much better quality, long lifetime and lowest cost. Also TC has low operating voltage to be worked but has no remote controlling systems than the other types.

\section{CONCLUSION}

This study demonstrates how the utilization of interactive glass panels could bring provide several benefits as power conservation, ecological safety, even building conceptual brilliance. Fixed technologies with chosen panels and immovable or moveable filters don't really permit for the year adjustment of thermal energy and luminance, limiting the quantity of transparent parts even during construction phase. Technologies that combine computerized interactive sun protection and constructing intelligent devices ensure optimal power efficiency and had significant implementation, operation, and management expenses and obstruct the sight from indoors to outdoors.

Instead, interactive glass panel, particularly electro chromic glazing, allows for the adjustment of the quantity of received energy from the sun depending on demanding requirement, enabling the realization of an external walls capable of completely adapting to seasonal changes, enhancing building actual quality including all climates, particularly hot climates.

Electro chromic systems are also more convenient than stationary technologies because they use less power for synthetic light sources and air heating or cooling during the different seasons, also they are less expensive than computer controlled filters technologies because of reduced system expenses and strategic planning.

The significant factors are the expensive expense of the devices, which is intended to fall as selling strategy and manufacturing procedures expand, and currently restricted knowledge exchange between specialists and users, which is also attributable to a shortage of technological standards. 
Instead of enhancing mostly on existing effective behavior, it seems that significantly lowering the expense of interactive glass panels, with a focus on coatings, manufacturing optimization, and simpler implementation, is much more important.

\section{REFERENCES}

1- Addington, DM., Schodek, DL., Smart materials and new technologies: for the architecture and design professions, Routledge.

2- Casini, M., 2015, Smart windows for energy efficiency of buildings, Article, Sapienza University of Rome. Pp. (273-274).

3- Casini, M., 2016, Smart buildings advanced materials and nanotechnology to improve energy efficiency and environmental performance, The Officers' Mess Business Centre, Royston Road, Duxford, UK, Pp. (305-318).

4- Cazes, B., 2011, Windows and glazed area technologies and materials in Europe, presented at the IEA (International Energy Agency) Building Envelope Technologies and Policies Workshop, Neuilly-sur-Seine, France.

5- Lamontagne, B., Barrios, P., Py, C., and Nikumb, S., 2009, The next generation of switchable glass: the Micro-blinds, Glass Performance Days.

6- Malmquist, D., and Sbar, N., 2013, The Benefits of Dynamic Glazing SAGE Electrochromics.

7- Khaldi, W., 2002, Thermochromic laminates and methods for controlling the temperature of a structure, Google Patents.

8- IEA, 2014, Tracking Clean Energy Progress 2014 OECD/IEA, Paris.

9- Apte, J., Arasteh, D., and Yu Joe Huang, P.E., 2003, Future Advanced Windows for ZeroEnergy Homes", ASHRAE Transactions, Volume 109, Part 2.

10- Saeli, M., Piccirillo, C., Parkin, Ip., Binion, R., Ridley, I., 2010, Energy modeling studies of thermo chromic glazing.

11- Schultz, Jm., Jensen Ki, 2008, Evacuated aerogel glazing, vacuum.

12- Schultz, Jm., Jensen, Ki., Kristiansen, Fh., 2005, Super insulating aerogel glazing.

13- Schwartz, M., 2002, Encyclopedia of smart materials, Vol. 1 \& Vol. 2, John Wiley \& Sons Inc., New York, Available From: Http://Www.Springer.Com

14- Schwartz, M., 2008, Smart materials, CRC Press, Taylor \& Francis Group, USA.

15- Wong, K. V., and Chan, R., 2013, Smart Glass and its potential in energy savings, Journal of Energy Resources Technology, Volume 136, Issue 1.

16- Xie, Z., Jin, X., Chen, G., Xu, J., Chen, D., and Shen, G., 2014, Integrated smart electro chromic windows for energy saving and storage applications, Chemical Communication, 2014. 